\title{
Towards Building Monolithic Computational Platform for SECI Model
}

\author{
S. M. F. D. Syed Mustapha \\ College of Computers and Information Technology, Taif University, Taif, KSA \\ Email: syed.malek@tu.edu.sa/smfdsm@yahoo.com
}

How to cite this paper: Syed Mustapha, S.M.F.D. (2016) Towards Building Monolithic Computational Platform for SECI Model. International Journal of Intelligence Science, 6, 29-41.

http://dx.doi.org/10.4236/ijis.2016.64004

Received: August 15, 2016

Accepted: October 20, 2016

Published: October 23, 2016

Copyright (@) 2016 by author and Scientific Research Publishing Inc. This work is licensed under the Creative Commons Attribution International License (CC BY 4.0).

http://creativecommons.org/licenses/by/4.0/

\begin{abstract}
SECI Model has been predominantly used by researchers as a framework for analyzing knowledge creation and knowledge sharing. It generalizes the application of the framework such that it is useable for various industries and disciplines such as in education, manufacturing, software development, finance, business and others. Its popularity has gained interest among researchers who explored the possibility to implement SECI model in computational environment. This paper presents the monolithic system that was designed and built to allow the SECI model activities to be performed in a full manner in a single platform. SECI model activities are studied and summarized to grasp the perceptions of the researchers of what are the activities that are classified under each SECI model phases. Based on these activities, we identified some selected activities to demonstrate the possibility of implementing the SECI Model in our KFTGA system. KFTGA (Knowledge Flow Tracer and Growth Analyzer) is a knowledge sharing platform that was built to support SECI Model activities.
\end{abstract}

\section{Keywords}

SECI Model, Knowledge Sharing, Knowledge Management, Learning Organization

\section{Introduction}

Innovation in an organization has been a long-standing issue and several conceptual innovation models have been discussed in the literature. Among the most popular one is SECI model proposed by Nonaka and Takeuchi [1] which is adopted for our research work. Most of the discussions in the literature focus 
towards applications of SECI model in the physical situation such that the members of the organization are presence in situ [2] [3] [4]. With advent of internet technologies and advanced software for document management, online communication channel, ICT has been used as tools to support some parts of SECI model activities [5]. For example, in the context of socialization, face-toface meetings can be performed via online meetings through modern communication technologies such as video conferencing. Other activities related to four quadrants of SECI model have been seen to be able to utilize ICT such that these activities are possible to be captured in computational form and later traceable as they are stored in digital format. Nevertheless, the technologies that are used for various quadrants of SECI model are not integrated in the same platform such that integration and consolidation of data are needed if those data need to be analyzed and processed together.

While there are growing interests among the organizations in adopting SECI model as the basis to measure the innovativeness of the employees, the organizational structure has also changed with the emerging of globalization such that the organizational structure and workflow structure spread beyond the local vicinity and connected virtually. The SECI model that was applied in a local setting has now expanded globally such that technologies must be used in engaging the community of learners in knowledge sharing and knowledge creation activities. The communities share their knowledge in a synchronous and an asynchronous mode, text-based discussion has dominated verbal discussion and geolocation is no longer a barrier for communication and in fact the online discussion has motivated some passive users to be more participative due to conveniences in communication. Generally, these technologies are Internet based in the form of web apps, web portals, client-server application or web-based social media, so-called Web 2.0 and the recent Web 3.0. Serious considerations are made on the available communication tools, knowledge sharing tools, social media and applications that are believed to support the activities within SECI model in which these shall be elaborated in the subsequent sections. Based on these literature, there are two points to be realized: a) wide acceptance among the researchers that SECI model activities can be or must be supported by ICT; b) the needs for an integrated platform of various technologies that shall allow the SECI model activities to be performed rather that segregating them in different software applications and databases. The latter point is the motivational factor for this paper to discuss further towards building a monolithic system to support various activities defined in SECI model quadrants.

In the subsequent sections, we introduce briefly the SECI model and its four main quadrants: what are the activities that are categorized within the four quadrants; what are the possible technologies that could support the activities and finally we describe our monolithic computational platform for supporting and capturing the SECI model activities. 


\section{Building Computational Model for SECI Model}

SECI model is a knowledge conversion theory that has been discussed by numerous researchers [6] [7] [8] [9] and the model is applied in their respective problems. However, we observe SECI model is referred as conceptual model in their analyses. We take different approach that we intend to build computational environment to facilitate the application of SECI model and subsequently detect the presence of each phase of knowledge conversion (S-C-E-I) automatically. While the SECI model shows the conversional knowledge flow is well-accepted as knowledge conversion theory, we pose two research questions as follows:

a) how would one build a computational platform to monitor the knowledge conversion?

b) how would one automatically monitor the maturity in the knowledge flow for multiple topics?

We view that in a knowledge sharing environment, a learner begins his learning journey in the first quadrant where knowledge is shared between learning community members through interactions in both synchronous and asynchronous way. A learner may be involved in one or more forum discussion on different topics and hence in the computational platform, a mechanism to be able to determine the conversion of the knowledge on different topics of discussion is necessary. For each of the topic, the SECI model profile will be established that describe members' involvement in that particular topics, knowledge maturity that has been attained by the member and knowledge network referencing which indicate the members that are mostly referred to for enquiries on certain topics.

\section{Activities in SECI Model and the Supporting Technologies}

In developing computational model for capturing activities of the learning communities, we examine authors who have determined activities for each SECI model quadrant on different application as shown in Table 1.

SECI model has also been applied in other areas such as virtual learning [7], knowledge creation in Russian context [14], product development performance [15], e-learning [16] and others. Even though the applications may be different but all of them have unanimous definition of the four SECI model knowledge conversion concepts. The only significant difference is that whether the application environment can be supported via computer technology or merely traditional method. For example, in the army forces situation, it is difficult to perform "combat operation" in a simulated environment to capture activities in digital format. Apart from some of the implausible military training situations, most of the SECI model applications are viable to be operated in computational platform.

Chatti et al. [17] are among the earliest researchers illustrating the categories of Web 2.0 emerging technologies that would support the knowledge conversion on the four quadrants of SECI Model as shown in Figure 1. The specific exam- 


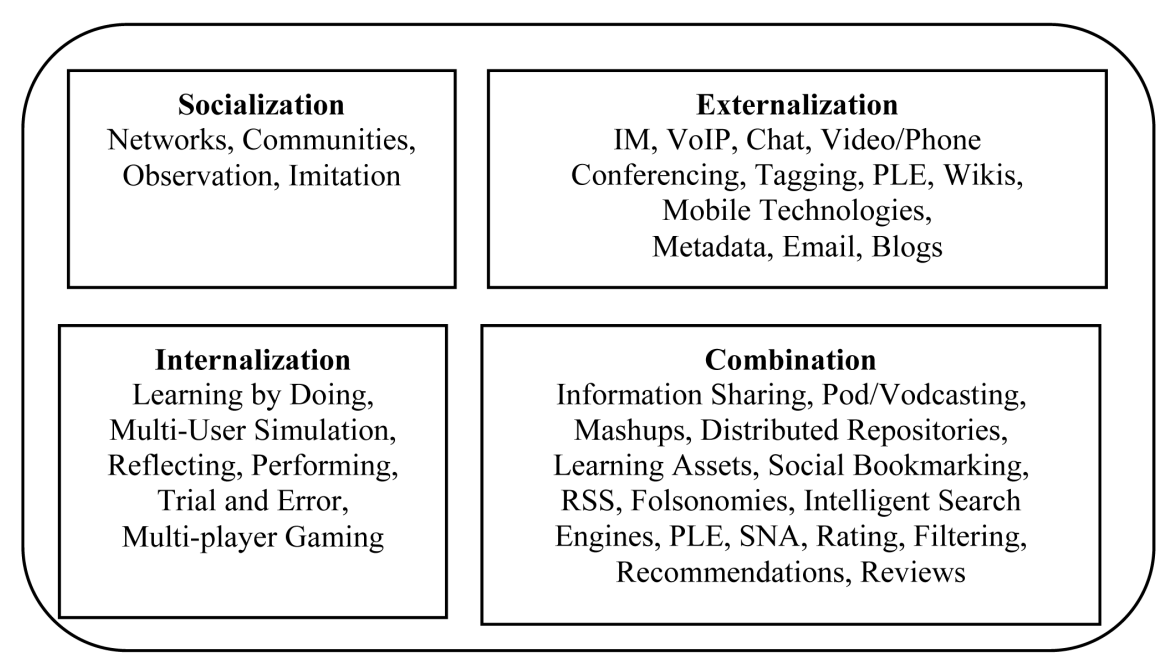

Figure 1. Web 2.0 Emerging Technologies (adapted from Chatti et al. [17]).

Table 1. Activities in SECI model.

\begin{tabular}{|c|c|}
\hline Authors & Knowledge Conversion Phases \\
\hline $\begin{array}{c}\text { Eerola and Jorgensen }[10]-S E C I \\
\text { Model in regional application }\end{array}$ & $\begin{array}{l}\text { Socialization: Working groups, panels, project groups, boards, networks, public forums } \\
\text { Externalization: Expert interviews, brainstorming, workshops, mind mapping, } \\
\text { Internet-based Delphi and other questionnaires } \\
\text { Combination: Foresight reports, technology lists, patent and publication analyses, } \\
\text { scenarios and decision trees, SWOT analysis, technology maps, risk analysis } \\
\text { Internalization: pilot projects, R \& D work, strategy work, weightings, priorities, } \\
\text { allocation of resources }\end{array}$ \\
\hline $\begin{array}{l}\text { Haag and Duan }[11]-S E C I \\
\text { Model in personal } \\
\text { knowledge development }\end{array}$ & $\begin{array}{l}\text { Socialization: Observation, imitation and learning by doing, sharing experiences } \\
\text { Externalization: Participation in social media such as discussion forum, blogs, } \\
\text { Instant Messaging and Online chat } \\
\text { Combination: Searching for materials on the web, watching videos or audio from the internet, } \\
\text { share the right sources to other potential recipients, collaboratively develop new materials } \\
\text { Internalization: perform self-assessment (quiz, test etc.) }\end{array}$ \\
\hline & $\begin{array}{l}\text { Socialization: Bulletin board discussion and simulation game activities; sharing background } \\
\text { information, open-threaded discussion-less formal than Externalization as this emphasize } \\
\text { more on building rapport and connection; create sense of social presence }\end{array}$ \\
\hline $\begin{array}{l}\text { Tee, M.Y. and Karney, } \\
\text { D. [12] - SECI Model in } \\
\text { Collaborative Learning }\end{array}$ & $\begin{array}{l}\text { Externalization: Threaded discussion; exploration and evaluation of ideas and relate them } \\
\text { through discussion and actions; some members take leadership role in discussion; } \\
\text { Combination: Generate new knowledge by combining ideas from different sources (discussion threads) } \\
\text { shared by group members; forming new strategic plan based on the multiple inputs; } \\
\text { Internalization: tacit knowledge is fully grasped after one or more cycles of } \\
\text { knowledge conversion; personal acknowledgement of mastering a topic. }\end{array}$ \\
\hline $\begin{array}{l}\text { Lis }[13]-S E C I \text { Model } \\
\text { in army forces }\end{array}$ & $\begin{array}{l}\text { Socialization: Counselling, coaching and mentoring to the less experienced military personnel } \\
\text { Externalization: Lesson learned-identifying lesson learned, determine actions and implementing the } \\
\text { changes, After Action Review-a verbal professional discussion that occur immediately after training, } \\
\text { combat operation and other missions ([15], pp 67) } \\
\text { Combination: knowledge that are acquired by military members are combined into doctrines } \\
\text { and other publications in which these are circulated to all members ([15], pp 70) } \\
\text { Internalization: individual training, collective training, exercises, drills and practice and } \\
\text { technology-based computer support training such as e-learning, advanced distributed learning (ADL), } \\
\text { computer-based training }(\mathrm{CBT}) \text {, mobile learning etc. }\end{array}$ \\
\hline
\end{tabular}


ples of the technologies are useful but for socialization and internalization, the proposed technologies are not clear.

Haag and Duan [11] identified measurement items for each of the knowledge conversion phases as shown in Figure 2. The same challenge in measuring items for socialization and internalization due to difficulties to track the movement of tacit knowledge.

The categorization of technologies for each quadrants as shown in Figure 1 and Figure 2 have been a good starting point for us to explore further on the possible ways to use technology as there are many literatures that describe the use of computer technologies for knowledge management but little has shown explicitly. Natek et al. [18] showed the categorization and the general information technology that supports the knowledge creation process. However, some of these technologies are generically referred to rather than being specific to the system's features and functions. For example, using expert system during internalization is rather vague as in developing expert system there are other phases such as knowledge acquisition, knowledge coding, etc that may applicable to other quadrants of SECI Model. Some of the technologies appear in more than one quadrant such as case-based reasoning systems and did not indicate which component of the systems that are used. Another work by Lee and Kelkar [19] enumerated 13 ICTs that can be used to support different phases of SECI Model. The paper surveys the perceptions among ICT practitioners in using ICTs such as Blog, Telephone, NetMeeting, E-mail, E-forums, People Finder and others to support knowledge management or knowledge sharing. The outcome of the survey indicates different preferences on ICT for different phases. The outcome shows that among the ICTs, email and telephone are the most preferred for all of the phases.

Based on the literature mentioned above, we form an understanding on what technologies that have been used and most importantly recognized as means to support the knowledge conversion flow. Since some of the previous attempts were not able to illustrate what were the plausible technologies especially on socialization and internalization, we determine to explore other alternatives. In

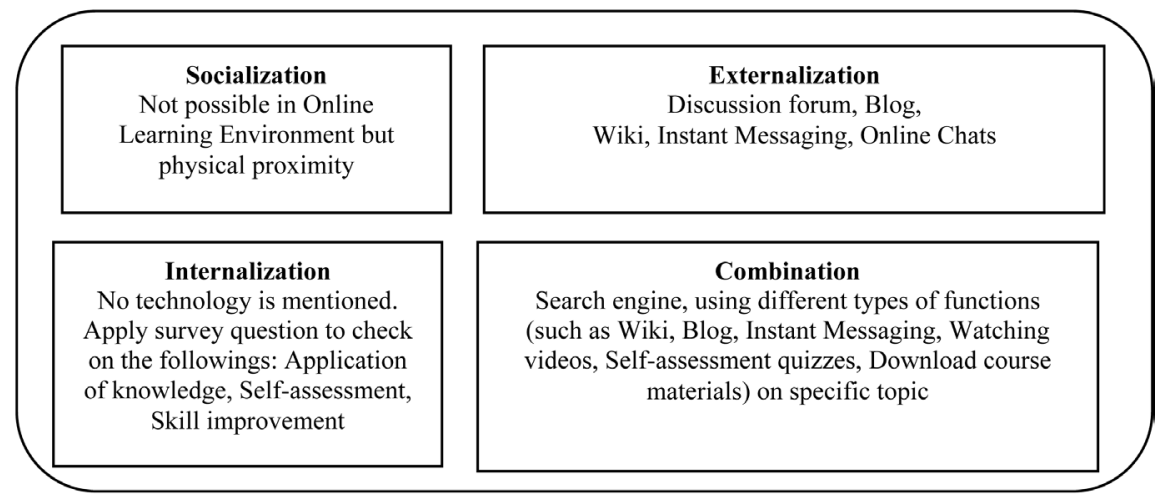

Figure 2. Measurement items for SECI model [11]. 
the following section, we discussed further the SECI model activities in the computational form and techniques to support them.

\section{SECI Model Activities in Computational Form}

The intention of our research is to develop a computational platform so that capturing the knowledge conversion flow is plausible. To do that, we identify the activities that could take place in computational environment for each of the SECI model quadrant as shown in Table 2.

Socialization requires an individual to build a comfortable interaction mood with the community members prior to engagement in knowledge sharing. We built user profile for every individual for the benefit of other members to view and to recognize the group members such that common interest group can be formed. At the socialization stage, the focus is not only on the content of the discussion but rather establishing the special interest group and taking the opportunity to get to know each other. Since the environment is created online, the physical interaction is not possible. It is recommended that every individual record his video to demonstrate his capabilities, skills, experiences, interest so much so that the introductory videos would sufficient for others to get acquaintance quickly with the owner of the video. This approach is similar to the physical face to face where the more interactions one has made with another person, the more acquainted one will be. Since the video is an asynchronous mode, an additional feature using a relayed audio recorded discussion concept is recommended for two reasons-recorded audio can be transcribed or tag for future retrieval and references and the relayed session allows the recording to be captured on individual in separate manner such that the owner of the voice can be recognized and stored systematically. That means, interjection and crisscross in the communication are not allowed. This mode of communication provides equal opportunity to everyone to talk and avoid dominance in the group discussions. The socialization process may happen in certain duration until the group members are comfortable to move on the next quadrant which is externalization.

Externalization emphasizes the group member to participate in creating new ideas, sharing new information, commenting on the existing topic discussions or create new public channel to incite new discussion threads such as wikis or

Table 2. Activities of SECI model in computational form.

\section{Knowledge Conversion Phases and Activities}

Socialization: Building User Profile, Creating Special Interest Group and Ice Breaking Session, Watching User-Generated Content Video, Video Exchanges, Relayed Audio Recorded Discussion

Externalization: Participation in Forum Discussion, Creation and Enhancement to the Public Channel Content (i.e. Wikis and Blogs), Chatting

Combination: File Sharing based on the Relevant Content and Distribution to the Relevant Group,

Internalization: Measuring the Density of the Participation for every individual against the contemporary participants 
blogs. Two roles as participation which are as group leader and followers in which one can be both for different group and no redundancy of role is permissible. One's ability to lead a group discussion on a topic attains a higher recognition in terms of mastery of the topic that he creates. The follower receives recognition based on the quality and quantity of the participated substances. The substances are in the form of text responses, uploaded materials such as videos, web pages, articles and multimedia objects. While the quantity is easy to be measured, the quality can be determined based on the policy to be set by the group administrator. Some of the examples of quality substances are such as the relevancy of the topic to the discussion, ability to resolve some outstanding issues, receiving responses and widely accepted by the community members.

Combination demonstrates one's overall understanding of the topic and subtopics. The ability to structure the contents of the repository in a taxonomical manner or classify the content based on the importance is an indication of one's skills in this quadrant. Since, a computational platform requires these actions to be tracked, it will be difficult to do as such as it requires some applications to be installed at one's private computer to monitor the actions continuously. Due to this reason, the activities are limited to two main modes-a) file sharing to the relevant special interest group; b) searching for appropriate materials in the learning space such as world wide web, knowledge repository in a local server or personal library in one's personal computer. While these actions may seem to be redundant with externalization, the significant difference is the ability to choose the relevant materials and not merely sharing any materials. In addition, sharing materials on specific topic can be a difficult task as one should have an overall understanding of the general discussion and topic being discussed as well as the topics at a deeper level. In the context of computational environment, these actions can be tracked and assessed using syntactical matching technique or context-based similarity methods.

Internalization deals with tacit knowledge that is transferred back to the individual. Since this process is implicit, our findings in the literature as discussed in the previous section (Section 3) indicated that no technology is capable to trace this process. In a non-computational environment, the internalization is conducted through self-assessment, quizzes, practical demonstration. In the proposed computational environment, the participation profiling is used as the basis to measure one's involvement in the internalization process. Using density to measure the participation online community has been discussed elsewhere and it used to measure in several dimensions such as participation linkages [20], number of posts [21] and others such as responses from others on the messages, relevant of the answers to the messages, average of messages for a certain period [22]. Corich et al. [23] had earlier explored the methods to analyze participation qualitatively for e-learning learners. Hence, our approach is to use the participative members to give due recognition to the individual of his proficiencies in 
specific knowledge area instead of directly measure his ability through self-assessment or quizzes as the topics are arbitrary and preparation for such assessment is practically implausible.

\section{Implementation of SECI Model in KFTGA}

The integrated system of SECI model is built in web-based environment. Users need to install the client browser application as shown in Figure 3. There are two levels of access which are administrators and members. Administrator creates group of special interest to initiate SECI model activities and the members are identified by the administrator. The client browser is custom made such that only certain SECI model activities are allowed using this browser. The client browser is needed as it captures information on the web activities (such as browsing, URL address, textual input, uploading/downloading online materials).

In this section, we describe the implementation aspect where some activities that have been identified in the previous section is considered for the implementation (refer to Table 2). Since tacit knowledge is intangible, its presence and flow will be traced through assumptions and also in an indirect manner. KFTGA (Knowledge Flow Tracer and Growth Analyzer) is built on SECI model concept to all the knowledge conversion process to be executed in the online environment [24].

The proposed activities in KFTGA are based on the four knowledge conversion phases mentioned above but adequately selected to demonstrate the processes in SECI model such that all activities can be conducted in the digital form. We illustrate the implementation scenario of the socialization process in Figure 4. Figure 4(a) shows a continuous social building session in asynchron-

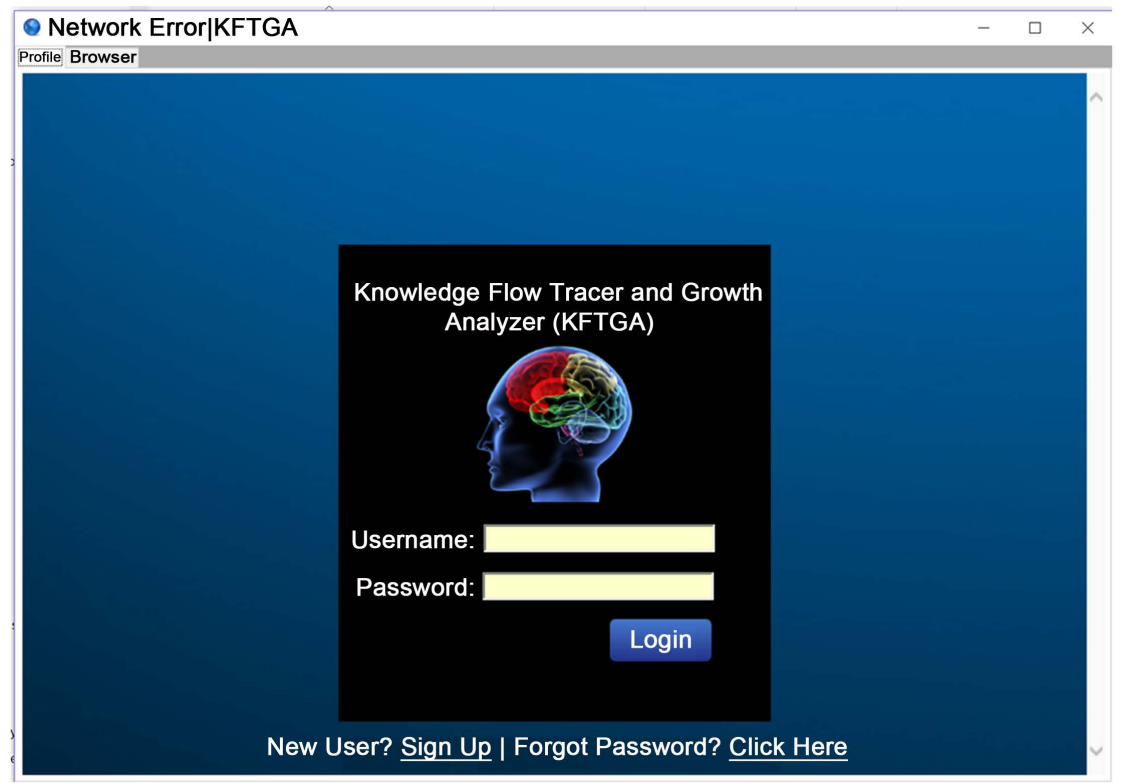

Figure 3. Client application. 


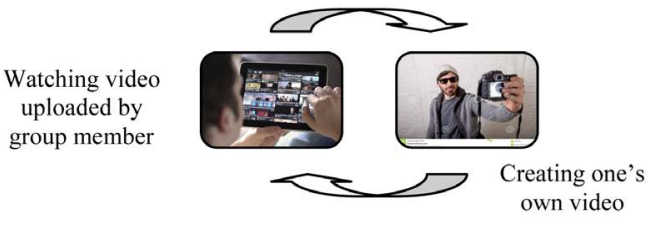

(a)

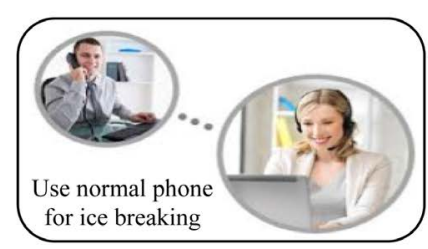

(b)

Figure 4. Socialization.

ous mode while Figure 4(b) is a synchronous and real time interaction. The action of a person in watching of someone video can be recorded in a log file as an evidence that tacit process is taking place. The computer system could record whose video that one has watched and the social link that indicates the familiarization of a person to the profile of another member increases as the frequency in visiting the person's video portal increases.

Every member creates his/her own personal portal and to visit portal of other members to earn recognition that he has successfully going through socialization process. In our implementation, every individual has his/her buddy list of whom he/she has formed to be in the group member, this is shown in Figure 5. An example of externalization process is when an individual engages in one or more communication channel discussing specific topic of interest. An individual could play different role in different channel and the recognition for each channel is earned separately. In our implementation, the communication channel prescribes wiki and blog styles besides the normal chatting forum as shown in Figure 6.

We have chosen file sharing and distribution of content to members as the activities under combination. The files can be in various multimedia objects including images, web site link, YouTube video links. The combination aspect of this action is on making the right associations of the multimedia objects to the right communication channel as shown in Figure 6.

For internalization, each user is scored against his involvement in each group of special interest. The participation is measured based on the recognition of each user's contribution to the group. In our implementation, the recognition is earned through one's involvement in a group discussion, active responses to discussion thread, sharing related resources and leading discussion group in channel. The scoring shown in Figure 7 is a general score which is calculated based on the number of participation for all types of participations. The report can be segregated by channels to indicate the scores for every individual on different topics. In our implementation, the internalization aspect is measured based on one's ability to master the knowledge and skill since internalization process is difficult to be traced and measured.

\section{Conclusions}

The implementation of SECI has been traditionally treated to be implemented in 


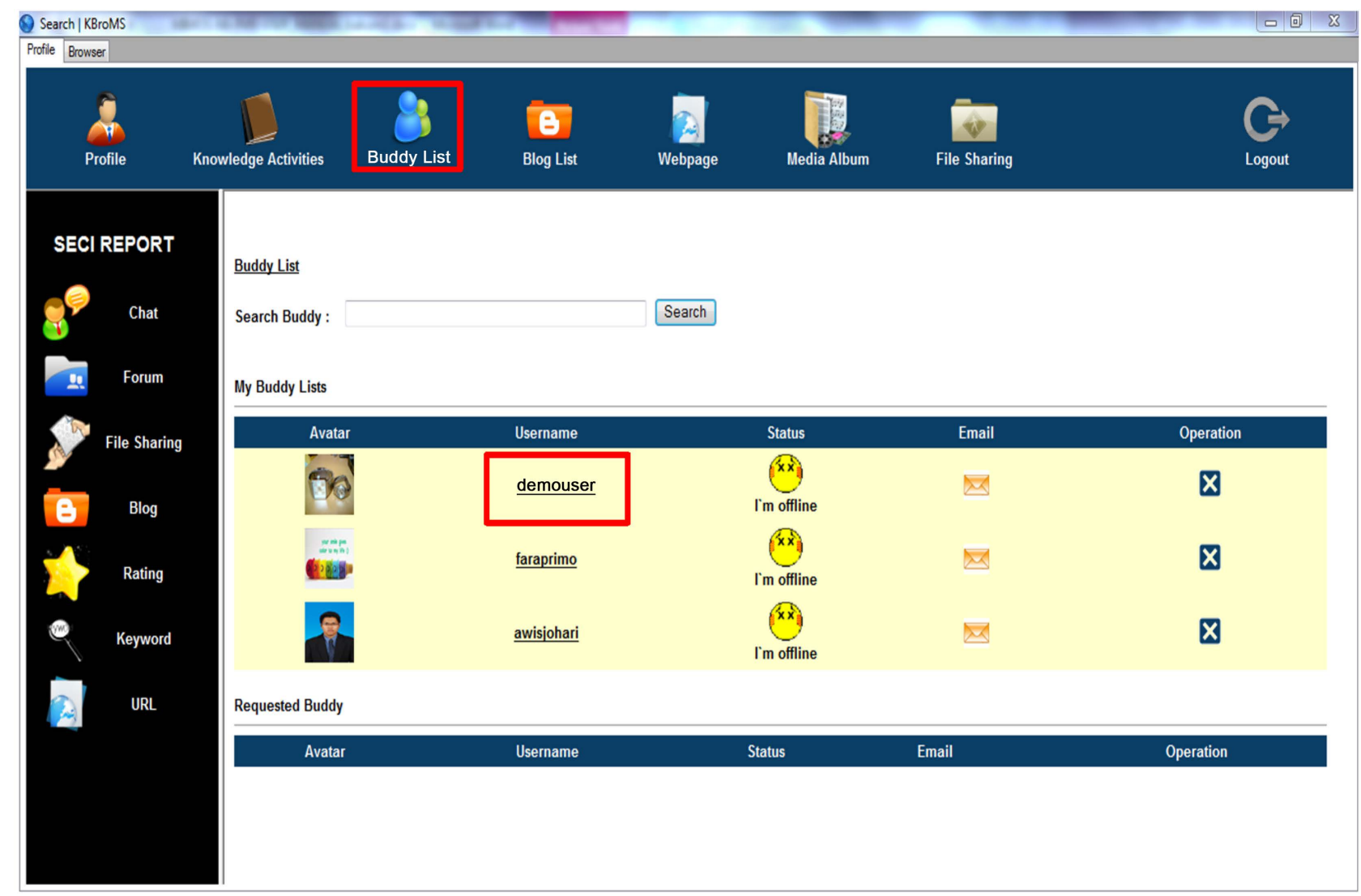

Figure 5. Buddy list.

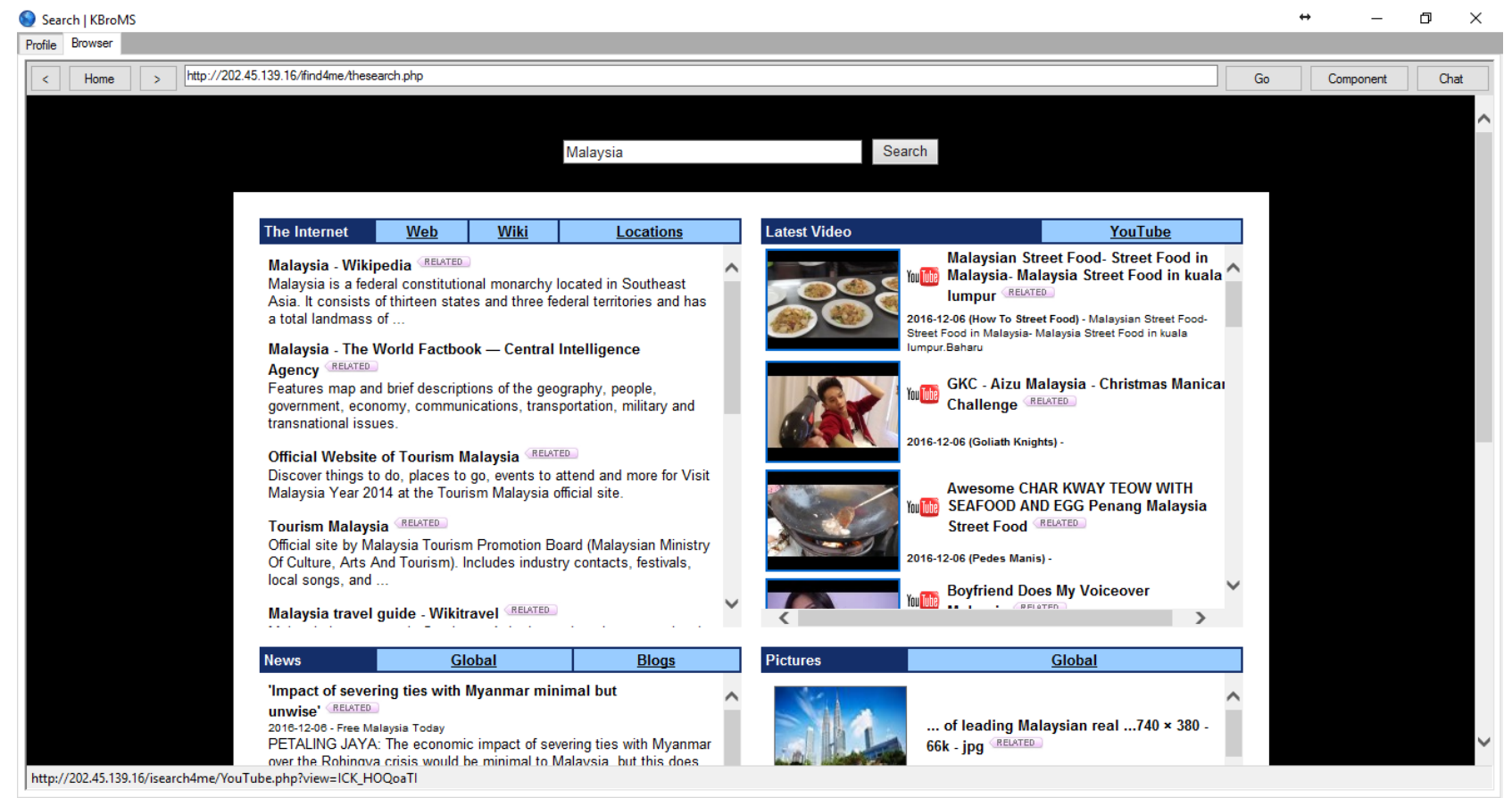

Figure 6. Browser for communication channel. 


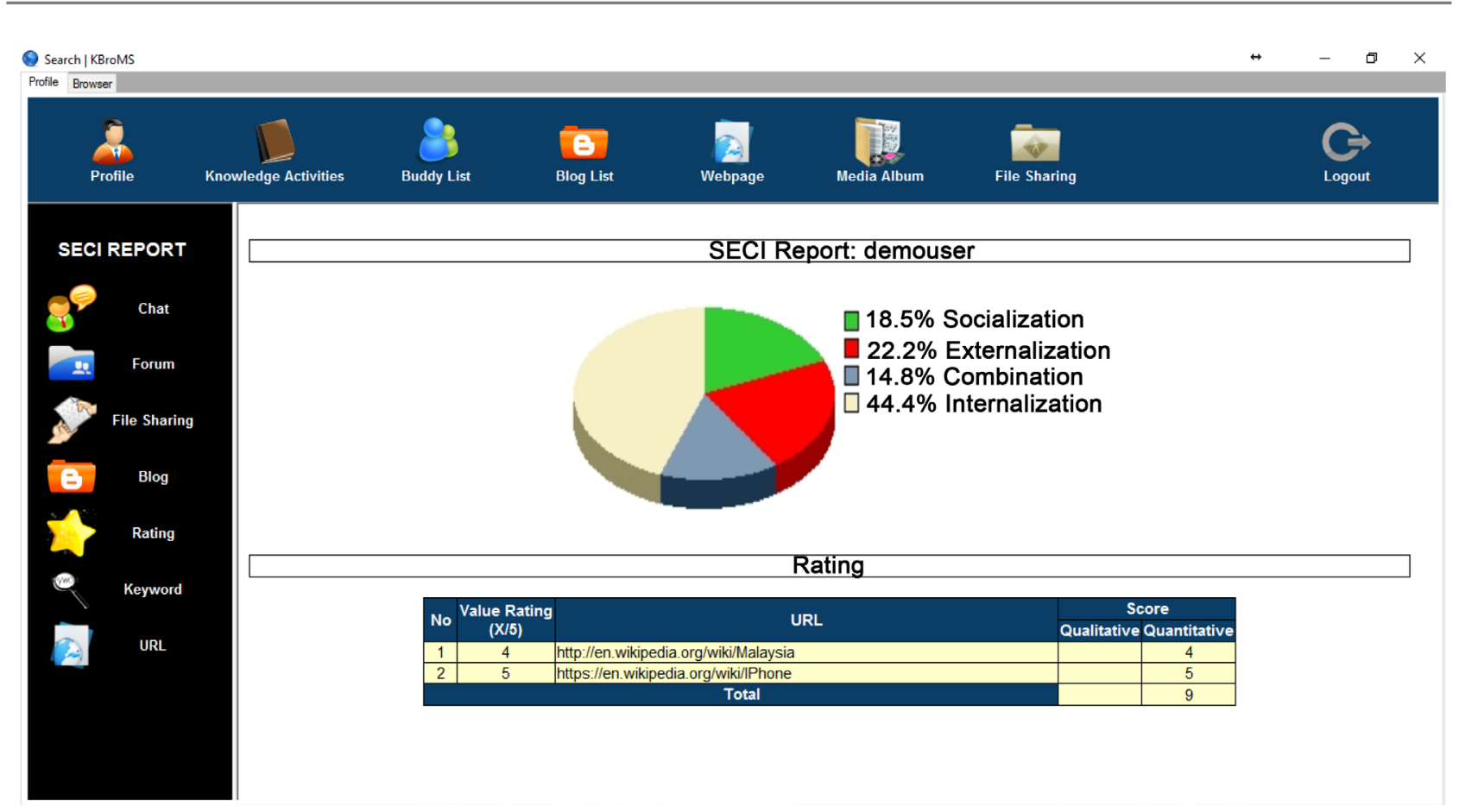

Figure 7. SECI model scoring chart.

general context and had never been specified to be described in computational environment. Our literature search reported in this paper has shown that there is a growing interest in implementing activities defined in SECI model in the ICT based environment and in recognizing SECI model as plausible model to be executed in a computational-based environment. Based on the literature, our intention to build a monolithic computational environment that supports the activities prescribed in SECI model is argued to be relevant and significant. It is also apparent that none in the literature has shown an effort to explore the possibility of executing SECI model fully in a computational platform and subsequently to build a monolithic computational environment that could support one to perform a complete process on SECI model based on selected activities. One may argue the needs for developing a monolithic platform that facilitates SECI activities when there are many applications such as Facebook, LinkedIn and others. There two main differences which are that the system that we built would allow an organization to have full control over what are the allowed activities to be performed in the platform and to decide what are the activities that fall under each S-E-C-I phase. Considering the communication technologies that develop and grow, the research to determine what are other potential technologies that could be deployed to support the SECI model activities and what are other activities that can be considered under each SECI model phase is a continuous effort.

Our research work is an impetus to other researchers who are interested to investigate further on SECI model implementation using any type of technolo- 
gies that could capture and detect the presence of SECI model activities. The current research assumes that the SECI model activities are executed in computer-based environment such that the technologies are confined towards computer-based and web-based. Hence, the activities that take place beyond the computer desktop are ought to be sensed and detected using other form of technologies that capture location, geo-physical movement, social connection, learning actions and others.

\section{Acknowledgements}

We would like to thank you to the team members from MIMOS (Malaysia) for the development of the KFTGA system.

\section{References}

[1] Nonaka, I. and Takeuchi, H. (1995) The Knowledge Creating Company: How Japanese Companies Create the Dynamics of Innovation. Oxford University Press, New York, 284.

[2] Cummings, J. (2003) Knowledge Sharing: A Review of Literature. The World Bank Operations Evaluation Department. http://ieg.worldbank.org/Data/reports/knowledge_eval_literature_review.pdf

[3] Hvorecky, J. (2012) Applying the SECI Model and Bloom's Taxonomy to the Preparation of Knowledge Management Specialists. http://www.cutn.sk/Library/proceedings/km_2012/PDF\%20FILES/Hvorecky.pdf

[4] Nonaka, I. and Konno, N. (1998) The Concept of Ba. Building Foundation for Knowledge Creation. California Management Review, 40, 40-54. https://doi.org/10.2307/41165942

[5] Sing, C.C. and Khine, M.S. (2006) An Analysis of Interaction and Participation Patterns in Online Community. Educational Technology \& Society, 9, 250-261.

[6] Finly, D. and Sathe, V. (2013) Nonaka's SECI Framework: Case Study Evidence and an Extension. Kindai Management Review, 1, 59-68.

[7] Hosseini, S.M. (2011) The Application of SECI Model as a Framework of Knowledge Creation in Virtual Learning. Asia Pacific Education Review, 12, 263-270. https://doi.org/10.1007/s12564-010-9138-5

[8] Rice, J. and Rice, B. (2005) The Applicability of the SECI Model to Multi-Organisational Endeavours: An Integrative Review. International Journal of Organisational Behaviour, 9, 671-682.

[9] Andreeva, T. and Ikhilchik, I. (2011) Applicability of the SECI Model of Knowledge Creation in Russian Cultural Context: Theoretical Analysis. Knowledge and Process Management, 18, 56-66. https://doi.org/10.1002/kpm.351

[10] Eerola, A. and Jorgensen, B.H. (2002) Technology Foresight in the Nordic Countries. Risø National Laboratory, Roskilde.

http://citeseerx.ist.psu.edu/viewdoc/download?doi=10.1.1.195.2797\&rep=rep1\&type $=\mathrm{pdf}$

[11] Haag, M. and Duan, Y. (2012) Understanding Personal Knowledge Development in Online Learning Environments: An Instrument for Measuring Externalisation, Combination and Internalisation. The Electronic Journal of Knowledge Manage- 
ment, 10, 39-47. www.ejkm.com/issue/download.html?idArticle=318

[12] Tee, M.Y. and Karney, D. (2010) Sharing and Cultivating Tacit Knowledge in an Online Learning Environment. International Journal of Computer-Supported Collaborative Learning, 5, 385-413. https://doi.org/10.1007/s11412-010-9095-3

[13] Lis, A. (2014) Knowledge Creation and Conversion in Military Organizations: How the SECI Model Is Applied within Armed Forces. Journal of Entrepreneurship, Management and Innovation, 10, 57-78.

[14] Andreeva, T. and Ikhilchik, I. (2011) Application of the SECI Model of Knowledge Creation in Russian Cultural Context: Theoretical Analysis, Knowledge and Process Management. Wiley Online Library, 18, 56-66.

[15] Ng, P.K., Goh, G.G.G. and Eze, U.C. (2011) The Role of Knowledge Management in Product Development Performance: A Review. Journal of Knowledge Management Practice, 12. http://www.tlainc.com/articl255.htm

[16] Wenhua, L. and Fushu, C. (2011) Evaluation Research Based on SECI Model in E-Learning. 2011 International Conference on Electrical and Control Engineering, Yichang, 16-18 September 2011, 6571-6573. https://doi.org/10.1109/ICECENG.2011.6056750

[17] Chatti, M.A., Klamma, R., Jarke, M. and Naeve, A. (2007) The Web 2.0 Driven SECI Model Based Learning Process. 7 th IEEE International Conference on Advanced Learning Technologies, Niigata, 18-20 July 2007, 780-782. https://doi.org/10.1109/icalt.2007.256

[18] Natek, S. and Zwilling, M. (2016) Knowledge Management Systems Support SECI Model of Knowledge-Creating Process. Joint International Conference 2016 Technology, Innovation and Industrial Management, Timisoara, 25-27 May 2016, 1123 1131. http://www.toknowpress.net/ISBN/978-961-6914-16-1/papers/ML16-251.pdf

[19] Lee, C.S. and Kelkar, R.S. (2013) ICT and Knowledge Management: Perspectives from the SECI Model. The Electronic Library, 31, 226-243. https://doi.org/10.1108/02640471311312401

[20] De Laat, M. (2002) Network and Content Analysis in an Online Community Discourse. Proceedings of the Conference on Computer Support for Collaborative Learning, Boulder, 7-11 January 2002, 625-626.

[21] Lee, H.Y. and Lee, H.W. (2016) Comparing Social Network Analysis of Posts with Counting of Posts as a Measurement of Learners' Participation in Facebook Discussions. The Turkish Online Journal of Educational Technology, 15, 11-19.

[22] Calvani, A., Fini, A., Molino, M. and Ranieri, M. (2009) Visualizing and Monitoring Effective Interactions in Online Collaborative Groups. British Journal of Educational Technology, 41, 213-226. https://doi.org/10.1111/j.1467-8535.2008.00911.x

[23] Corich, S., Kinshuk and Hunt, L.M. (2004) Assessing Discussion Forum Participation: In Search of Quality. International Journal of Instructional Technology and Distance Learning, 1, 1-12. http://www.itdl.org/journal/dec_04/article01.htm

[24] Syed Mustapha, S.M.F.D. (2012) KFTGA: A Tool for Tracing Knowledge Flow and Knowledge Growth in Knowledge Sharing Environment. Journal Information, Knowledge, Systems Management, 11, 205-224. 
Submit or recommend next manuscript to SCIRP and we will provide best service for you:

Accepting pre-submission inquiries through Email, Facebook, LinkedIn, Twitter, etc. A wide selection of journals (inclusive of 9 subjects, more than 200 journals)

Providing 24-hour high-quality service

User-friendly online submission system

Fair and swift peer-review system

Efficient typesetting and proofreading procedure

Display of the result of downloads and visits, as well as the number of cited articles Maximum dissemination of your research work

Submit your manuscript at: http://papersubmission.scirp.org/

Or contact ijis@scirp.org 